\title{
Development and In Vitro Characterisation of Transdermal Therapeutic System of Ketorolac Tromethamine
}

\author{
Srilatha Malvey ${ }^{1}$, Venkateshwar Rao J.2. Kottai Muthu A. ${ }^{3}$ \\ ${ }^{1}$ Department of Pharmaceutics, Talla Padmavathi College of Pharmacy, Warangal, Telangana, India. \\ ${ }^{2}$ Department of Pharmaceutical Chemistry, Talla Padmavathi College of Pharmacy, Warangal, Telangana, \\ India. ${ }^{3}$ Department of Pharmacy, Annamalai University, Annamalai Nagar, Tamilnadu, India.
}

\section{ABSTRACT}

\section{BACKGROUND}

Among the various conventional formulations, transdermal patches are a novel therapeutic system to deliver the drugs. This investigation aims to develop and evaluate the matrix-type transdermal drug delivery system of ketorolac tromethamine (KTR) for sustained delivery.

\section{METHODS}

A prospective study of transdermal therapeutic patch of ketorolac tromethamine was developed with different concentrations of polymer HPMC E15 with PEG 400 as plasticiser and DMSO as a permeation enhancer by using solvent casting technique.

\section{RESULTS}

The physicochemical compatibility of the drug and polymer is studied by infrared spectroscopy and it was found that there is no interaction between drug and excipients used in the formulation. The formulated patches were analysed for weight variation, drug content, thickness, moisture content, and folding endurance. All the prepared formulations showed good integrity. In vitro dissolution test was carried out in the phosphate buffer pH 7.4 as a dissolution medium in USP type II apparatus. The cumulative percentage of drug dissolved was determined with and without penetration enhancer.

\section{CONCLUSIONS}

Formulation F6 batch with highest percentage of permeation enhancer showed 96.89 $\%$ of drug release up to 24 hrs., and optimised formulation batch F5 release follows Peppas plot with a super-case II transport mechanism.

\section{KEY WORDS}

Matrix Type TDDS, Ketorolac Tromethamine, In Vitro, Drug Distribution in Patch
Corresponding Author:

Dr. Kottai Muthu A,

Department of Pharmacy,

Annamalai University,

Annamalainagar - 608 002,

Tamilnadu, India.

E-mail: akottaimuthu@gmail.com

DOI: $10.14260 /$ jemds/2021/19

How to Cite This Article:

Malvey S, Rao VJ, Muthu AK. Development and in vitro characterisation of transdermal therapeutic system of ketorolac tromethamine. J Evolution Med Dent Sci 2021;10(02):93-97, DOI: 10.14260/jemds/2021/19

Submission 02-09-2020,

Peer Review 06-11-2020,

Acceptance 12-11-2020,

Published 11-01-2021.

Copyright (C) 2021 Srilatha Malvey et al. This is an open access article distributed under Creative Commons Attribution License [Attribution 4.0 International (CC BY 4.0)] 


\section{BACKGROUND}

Transdermal drug delivery system (TDDS) is a sustained drug delivery of active pharmaceutical ingredients (API) into systemic circulation at a predetermined rate and it has advantages compared to the oral route of administration, especially in the elderly and bedridden patients. This type of formulation is particularly useful with chronic inflammatory disorder; this dosage form allows for the avoidance of the patient's unwillingness to swallow. It helps in maintaining constant drug blood levels over an extended time period and improves compliance, because there is no need for the patient to recall to take his or her medication or carry pills for further administrations of drug in the day. When compared to oral route, this route has many benefits such as sustaining drug delivery, bypassing first-pass metabolism maintaining a constant and prolonged drug level in plasma, minimizing patient variability, and making it possible to terminate treatment when necessary. Till the date various drugs (scopolamine, nitroglycerine, clonidine, estradiol, nicotine, isosorbide dinitrate) has been successfully incorporated into transdermal delivery system for clinical benefits under acute condition to treat various disorders (motion sickness, heart failure, high blood pressure, hormone replacement therapy, depressive-spectrum disorders). Ketorolac has been reported to have similar efficacy to narcotic analgesic, where it does not show any addiction problem. Ketorolac is 800 times more potent than other analgesic and show moderate antiinflammatory activity.

Nonsteroidal anti-inflammatory drugs (NSAIDs) are mostly used for the preparation of transdermal patches for the treatment of inflammation; among the dosage forms, transdermal patches are considering as safer and convenient to use. A novelty in incorporation of nonsteroidal antiinflammatory drugs into dosage form improves therapeutic performance and reduces the side effects associated with conventional dosage form of nonsteroidal anti-inflammatory drugs. In the present investigation, an attempt is made to develop matrix type transdermal patches of ketorolac tromethamine using simple polymer like hydroxy propyl methyl cellulose E-15. Ketorolac is a nonsteroidal antiinflammatory drug and has antipyretic, analgesic, and antiinflammatory properties. Which shows extensive hepatic metabolism by hydroxylation and conjugation and has T-half of $5 \mathrm{hr}$. It is directed for short term management of acute pain. Clinicians may select to initiate ketorolac to manage postoperative pain, spinal and soft tissue pain, rheumatoid arthritis, osteoarthritis, ankylosing spondylitis, menstrual disorders, and headaches. Regardless of the aetiology of pain, patients should use the lowest possible dose, and avoid using ketorolac for an extended period (ideally $\leq 5$ days). Because of observed gastric ulcers and perforations. A benefit of selecting ketorolac over other analgesics with parallel potency and does not appear to be a risk of addiction with ketorolac use. Ketorolac blocks prostaglandin synthesis. Prostaglandin has the potency to show effects in the body and their main role is to induce pain and inflammation. ${ }^{1}$

The main purpose of the present study was to develop transdermal patches of ketorolac tromethamine to ensure prolonged drug release and to avoid frequency dosing with fluctuation of blood levels, a dosage form for alternative, nonoral delivery system has been investigated for sustained release of drug for entire day. Transdermal drug delivery system offers a number of advantages like potential decrease in side effects, termination of therapy and improved patients compliance.

\section{METHODS}

A prospective study of ketorolac tromethamine was obtained from Cadila Pharmaceuticals Ltd., Ahmedabad. Hydroxypropyl methylcellulose E15 (HPMC E-15), ethyl cellulose (EC), and methyl cellulose (MC) were obtained as a gift sample from $\mathrm{Dr}$ Reddy's Laboratories, Hyderabad; dimethyl sulfoxide (DMSO) was purchased from Finar Chemicals. Pvt. Ltd., Ahmedabad. Dichloromethane (DCM) was purchased from S.D. Fine Chem. Ltd., Mumbai; polyethylene glycol (PEG), methanol were purchased from Qualikems Fine Chem. Pvt. Ltd., Vadodara, India. All the chemicals used are of analytical reagent grade.

\section{Spectrum Scanning}

$10 \mu \mathrm{g} / \mathrm{mL}$ concentration of drug is taken for spectrum scanning, scanning was done from 400 to $200 \mathrm{~nm}$, using UV spectrophotometer, (UV - 1800) Shimadzu Corporation. Standard graph was also constructed for both the solvents (water and phosphate buffer $\mathrm{pH}$ 7.4).

\section{Preparation of Transdermal Patches}

The method used for the preparation of film is the solvent casting technique. Composition of transdermal films containing ketorolac tromethamine along with polymers such as HPMC E15, EC, and MC, individual patches performed by dissolving in the mixture of DCM; methanol (1:1) ratio, the result obtained from preliminary trails batch with HPMC E 15 was found to be the best film forming polymer in appearance of film. Hence, among them HPMC E15 was selected for further study. Initially, HPMC E15 was soaked overnight in DCM alone and in DCM: methanol (1:1). Therefore, polymer was dissolved in the mixture of solvents or solvent with the help of magnet, stirred for about $1 \mathrm{hr}$ and soaked overnight, the further KTR was dispersed in the polymer matrix along with plasticiser (PEG 400) and permeation enhancer (DMSO) and mixed for 2 hr using a $2 \mathrm{MLH}$ magnetic stirrer (REMI, India). The $10 \mathrm{~mL}$ prepared solution was cast in a petri dish having diameter of $6.7 \mathrm{~cm}$, and dried at room temperature by covering petri dish with an inverted funnel for $24 \mathrm{hr}$, the membrane was taken and out cut into $5.44 \mathrm{~cm}^{2}$ packed in aluminium foil and stored in a desiccator until further use. The composition of prepared transdermal is shown in table 1.

\begin{tabular}{|ccccccc|}
\hline Ingredients (mg) & F1 & F2 & F3 & F4 & F5 & F6 \\
\hline KTR & 200 & 200 & 200 & 200 & 200 & 200 \\
HPMCE - 15 & 100 & 200 & 100 & 200 & 200 & 200 \\
DCM & 10 & 10 & & & & \\
DCM:Methnol (1:1) (mL) & & & 10 & 10 & 10 & 10 \\
PEG - 400 \% v / v & 5 & 5 & 5 & 5 & 5 & 5 \\
DMSO \% v / v & & & & 4 & 8 \\
\hline Table 1. Composition of Transdermal Patches \\
\hline
\end{tabular}




\section{Patches Area Calculations}

Area of petri dish reflects area of membrane (patch) that is $36.298 \mathrm{~cm}^{2}$ in which $200 \mathrm{mg}$ of the drug is present. The membrane was cut into a number of pieces containing an area of $5.447 \mathrm{~cm}^{2}$ in which it contains $30 \mathrm{mg}$ of the drug as the recommended dose for once-a-day patch.

\section{Characterisation of Transdermal Patches Weight Variation Test}

The patches were subjected to weight variation, the selected three patches randomly weighed from each batch and the average was calculated by using digital balance (Keroy India). ${ }^{2}$

\section{Thickness}

The thickness of the prepared films was measured by a screw gauge with zero error at five different sites, for five films from each batch. Calculated individually and average was calculated by using Screw gauge, Micro, India. ${ }^{3}$

\section{Drug Content}

Each patch of $5.44 \mathrm{~cm}^{2}$ equivalent to $30 \mathrm{mg}$ of the drug from different formulations was dissolved in phosphate buffer $\mathrm{pH}$ 7.4 and shaken continuously for the $24 \mathrm{hr}$, using a magnetic stirrer to extract the drug from the patch, ${ }^{4}$ the desired volume of the filtrate was taken and diluted with phosphate buffer $\mathrm{pH}$ 7.4, amount of drug content was measured spectrophotometrically at the $\lambda \max$ of $322 \mathrm{~nm}$.

\section{Folding Endurance}

The folding endurance of patches was performed by repeatedly folding a strip at the same place until it breaks. The number of times required to break the film was noted as its folding endurance. This is important to check the ability of film to brittleness. ${ }^{5}$

\section{Percentage of Moisture Uptake}

The desired area with a known weight of three patches in each formulation was kept in a desiccator at room temperature for $24 \mathrm{hr}$, which are exposed to $84 \%$ relative humidity (a saturated solution of aluminium chloride) in a desiccator. Periodically weight of patch was measured until a constant weight was obtained. The moisture uptake was calculated as the difference between final and initial weight with respect to the initial weight. ${ }^{5}$

\section{Percentage of Moisture Content}

The desired area with a known weight of three patches in each formulation batch was kept in a desiccator at room temperature for $24 \mathrm{hr}$. Then it is exposed to desiccators containing activated silica individual films that were weighted periodically until they showed a constant weight. The moisture content was calculated as the difference between the initial and final weight with respect to the final weight. ${ }^{6}$

\section{In Vitro Drug Release Studies}

The in vitro drug release studies from ketorolac transdermal patches were performed using Electrolab dissolution test apparatus USP-II. The commercially available adhesive layer was used as a backing membrane for patches, it was further fixed to a glass slide with the help of adhesive, and the backing membrane helps in the unidirectional flow of drug from the membrane. The entire set was placed at the bottom of the vessel in $500 \mathrm{~mL}$ of $7.4 \mathrm{pH}$ phosphate buffer with its release surface facing upwards, dissolution test was performed with a paddle speed of $50 \mathrm{rpm}$ at $37 \pm 0.5{ }^{\circ} \mathrm{C}$. Periodically $2 \mathrm{~mL}$ of sample were withdrawn and the absorbance of a drug in the solution was measured using UV spectrophotometrically at $322 \mathrm{~nm}$ taking phosphate buffer $\mathrm{pH} 7.4$ as blank. The cumulative percentage of drug release at various time intervals were calculated and plotted against time. ${ }^{7}$

\section{FTIR Analysis}

Infrared spectroscopy was carried out for pure drug, and finalised batch between $400 \mathrm{~cm}^{-1}-4000 \mathrm{~cm}^{-1}$ where samples are placed directly on the probe for analysis with Bruker. ${ }^{8}$ FTIT spectra were recorded to assess that compatibility of the drug and final formulation

\section{Statistical Analysis}

Results were communicated as mean \pm SD of 5 determinations.

\section{RESULTS}

\section{Spectral Scanning of Pure Drug}

For Lambda max identification, $10 \mu \mathrm{g} / \mathrm{mL}$ of concentration is taken for analysis and maximum absorbance was found to be at $322 \mathrm{~nm}$, both in water and phosphate buffer (PB) pH 7.4.

\section{Standard Graph of KTR in Water}

$100 \mathrm{mg}$ of the drug is taken and dissolved in $100 \mathrm{~mL}$ of water called a primary stock solution with a concentration of $1 \mathrm{mg} /$ $\mathrm{mL}$ from this $1 \mathrm{~mL}$ is taken and diluted with $99 \mathrm{~mL}$ of water called a second stock solution of $10 \mu \mathrm{g} / \mathrm{mL}$. From second stock solutions $2,4,6,8,10 \mathrm{~mL}$ was taken, and the renaming portion was diluted up to $10 \mathrm{~mL}$ to make the concentration of $2,4,6,8$, $10 \mu \mathrm{g} / \mathrm{mL}$. with linearly of $\mathrm{R}^{2}=0.9956 . \mathrm{y}=0.09 \mathrm{x}+0.0304$.

\section{Standard Graph of KTR in PB pH 7.4}

$100 \mathrm{mg}$ of the drug is taken and dissolved in $100 \mathrm{~mL}$ of phosphate buffer $\mathrm{pH} 7.4$ called as a primary stock solution with a concentration of $1000 \mu \mathrm{g} / \mathrm{mL}$ from this $1 \mathrm{ml}$ is taken and diluted up to $100 \mathrm{~mL}$ of phosphate buffer $\mathrm{pH} 7.4$ called as a secondary stock solution of $10 \mu \mathrm{g} / \mathrm{mL}$. From secondary stock solutions $2,4,6,8,10 \mathrm{~mL}$ was taken, and the remaining portion was diluted up to $10 \mathrm{~mL}$ of phosphate buffer $\mathrm{pH} 7.4$ to make the concentration of $2,4,6,8,10 \mu \mathrm{g} / \mathrm{mL}$, with $\mathrm{R}^{2}$ value of 0.9978 and $Y=0.108 x+0.0264$.

\section{FTIR Studies}

In FTIR spectra of finalised formulation patch contains characteristics of Aromatic $\mathrm{C}=\mathrm{C}$ band found at $1601.63 \mathrm{~cm}^{-1}$, $\mathrm{N}=\mathrm{C}$ band found at $3458.29 \mathrm{~cm}^{-1}$ and $\mathrm{C}-\mathrm{H}$ band found at $2955.45 \mathrm{~cm}^{-1}$ All characteristic peaks of ketorolac tromethamine were observed in the FTIR spectra of finalised F5 formulation. The results showed that there is no chemical 
interaction after the formulation and found that the drug is stable in all the formulations as shown in table 2.

\begin{tabular}{|cccc|}
\hline Sl. No & $\begin{array}{c}\text { Characteristic Peak of } \\
\text { KTR }\end{array}$ & Range ( $\mathbf{c m}^{-\mathbf{1}}$ ) & $\begin{array}{c}\text { Peak Obtained in } \\
\text { Finalized Formulation } \\
\text { (F5) }\end{array}$ \\
1 & Aromatic C = C & $1590-1620$ & 1601.63 \\
2 & N $=$ C & $3440-3462$ & 3458.29 \\
3 & C - H & $2938-2975$ & 2955.45 \\
\hline \multicolumn{3}{|c|}{ Table 2. Characteristic Peaks of FTIR } \\
\hline
\end{tabular}

\begin{tabular}{|c|c|c|c|c|c|c|c|}
\hline ì & 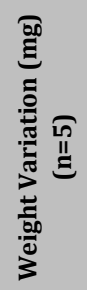 & 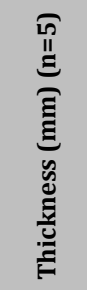 & 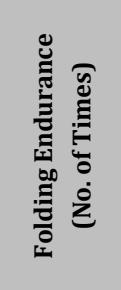 & 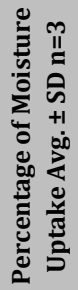 & 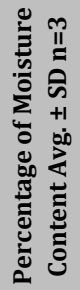 & 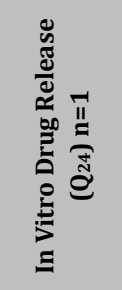 & 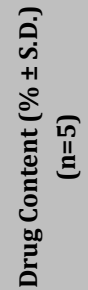 \\
\hline F1 & $\begin{array}{l}0.728 \pm \\
0.0109\end{array}$ & $\begin{array}{c}0.536 \pm \\
0.023\end{array}$ & $84.2 \pm 6.30$ & $\begin{array}{l}1.23 \pm \\
0.047\end{array}$ & $\begin{array}{l}2.12 \pm \\
0.037\end{array}$ & $66.87 \%$ & $\begin{array}{c}96.80 \pm \\
1.82 \\
(n=5)\end{array}$ \\
\hline F2 & $\begin{array}{l}0.896 \pm \\
0.0114\end{array}$ & $\begin{array}{c}0.720 \pm \\
0.007\end{array}$ & $88.0 \pm 2.19$ & $\begin{array}{l}2.71 \pm \\
0.020\end{array}$ & $\begin{array}{l}2.96 \pm \\
0.020\end{array}$ & $55.23 \%$ & $\begin{array}{c}93.60 \pm \\
0.675\end{array}$ \\
\hline F3 & $\begin{array}{l}0.964 \pm \\
0.0054\end{array}$ & $\begin{array}{c}0.742 \pm \\
0.023\end{array}$ & $81.4 \pm 4.50$ & $\begin{array}{l}2.06 \pm \\
0.037\end{array}$ & $\begin{array}{l}2.05 \pm \\
0.017\end{array}$ & $75.91 \%$ & $\begin{array}{c}90.20 \pm \\
1.066\end{array}$ \\
\hline F4 & $\begin{array}{l}0.968 \pm \\
0.0334\end{array}$ & $\begin{array}{c}0.760 \pm \\
0.017\end{array}$ & $\begin{array}{c}112.2 \pm \\
1.48\end{array}$ & $\begin{array}{l}2.83 \pm \\
0.011\end{array}$ & $\begin{array}{l}1.62 \pm \\
0.034\end{array}$ & $68.44 \%$ & $\begin{array}{c}95.55 \pm \\
1.204\end{array}$ \\
\hline F5 & $\begin{array}{l}1.002 \pm \\
0.0179\end{array}$ & $\begin{array}{c}0.762 \pm \\
0.017\end{array}$ & $\begin{array}{c}99.20 \pm \\
4.60\end{array}$ & $\begin{array}{l}3.34 \pm \\
0.028\end{array}$ & $\begin{array}{l}1.95 \pm \\
0.055\end{array}$ & $96.89 \%$ & $\begin{array}{c}96.20 \pm \\
0.908\end{array}$ \\
\hline F6 & $\begin{array}{l}1.222 \pm \\
0.0192\end{array}$ & $\begin{array}{c}0.762 \pm \\
0.013\end{array}$ & $\begin{array}{c}127.6 \pm \\
13.12\end{array}$ & $\begin{array}{l}3.91 \pm \\
0.010\end{array}$ & $\begin{array}{l}3.74 \pm \\
0.040\end{array}$ & $\begin{array}{c}80.61 \% \text { at } \\
12 \mathrm{hr} .\end{array}$ & $\begin{array}{c}98.80 \pm \\
1.242\end{array}$ \\
\hline \multicolumn{8}{|c|}{ Table 3. Physical Evaluation of KTR Transdermal Patches } \\
\hline
\end{tabular}

\begin{tabular}{|ccccccc|}
\hline Time (hr) & F1 & F2 & F3 & F4 & F5 & F6 \\
0 & 0 & 0 & 0 & 0 & 0 & 0 \\
1 & 02.04 & 00.25 & 04.35 & 02.00 & 04.69 & 08.72 \\
2 & 03.67 & 01.45 & 05.28 & 03.55 & 07.54 & 13.51 \\
4 & 09.42 & 04.26 & 12.38 & 10.44 & 16.51 & 30.11 \\
6 & 14.51 & 08.21 & 17.71 & 16.39 & 20.74 & 42.50 \\
8 & 25.66 & 15.89 & 29.47 & 26.88 & 36.81 & 55.28 \\
10 & 32.50 & 23.69 & 36.64 & 33.74 & 49.73 & 64.36 \\
12 & 46.71 & 32.73 & 50.59 & 48.22 & 59.38 & 80.61 \\
24 & 66.87 & 55.23 & 75.91 & 68.44 & 96.89 & --- \\
\hline \multicolumn{7}{c}{ from Transdermal Patch (n= 1) } \\
\hline
\end{tabular}

\section{Release Kinetics}

To understand the order of release of the drug from the prepared patches, the released data from the in vitro release studies are fitted into zero-order, first-order Higuchi plot, and Peppas plot. ${ }^{9}$

\begin{tabular}{|cccccc|}
\hline F Code & $\begin{array}{c}\text { Zero } \\
\text { Order }\end{array}$ & $\begin{array}{c}\text { Peppas } \\
\text { Plot }\end{array}$ & $\begin{array}{c}\text { Higuchi } \\
\text { Plot }\end{array}$ & $\begin{array}{c}\text { First } \\
\text { Order }\end{array}$ & $\begin{array}{c}\text { Diffusion } \\
\text { Exponent "n" }\end{array}$ \\
F1 & 0.9581 & 0.9830 & 0.8922 & 0.9766 & 1.1937 \\
F2 & 0.9744 & 0.9773 & 0.8494 & 0.9745 & 1.7402 \\
F3 & 0.9707 & 0.9711 & 0.9053 & 0.9801 & 0.9983 \\
F4 & 0.9577 & 0.9822 & 0.9007 & 0.9791 & 1.2119 \\
F5 & 0.9784 & 0.9840 & 0.9078 & 0.9059 & 1.0148 \\
F6 & 0.9963 & 0.9940 & 0.9346 & 0.9517 & 0.9139 \\
\hline \multicolumn{7}{c}{ Table 5. Release Kinetic Data of Transdermal Patches } \\
\hline
\end{tabular}

Among various release kinetics, the Peppas plot seemed to be the most appropriate model describing release from formulation F5. On the other hand, " $n$ " value is 1.0148 indicating the amount of released drug was follows by super case II transport mechanism.

\section{DISCUSSION}

Prepared patches with different concentrations were found to be smooth and transparent, non-sticky and homogenous in drug dispersion drug is not distributed homogeneously.

The analytical method development was done by scanning a drug at $10 \mu \mathrm{g} / \mathrm{mL}$ concentration, where maximum absorbance was found at $322 \mathrm{~nm}$ both in water and phosphate buffer pH 7.4 amount of drug dissolved is measured against the standard graph developed for pure water with $\mathrm{R}^{2}$ value of 0.997, moisture uptake study shows that as the concentration of polymer increases the percentage of moisture uptake also increases. Among the batches, F5 batch showed higher moisture absorption. This is due to their higher concentrations of polymer, permeation enhancer, and plasticizer. The least percentage of moisture absorption was found for $\mathrm{F} 1$ patch as compared to F5; this is due to the concentration of polymer and absence of methanol as a solvent in formulation batch. It was found that as the concentration of polymer \& permeation enhancer increases, the weight of patches increases and even thickness too, as shown in table 3. It was also found that the patches contain a higher concentration of permeation enhancer showed higher folding endurance due to more flexibility of patches there was no significant difference found in the drug content among the patches indicating content uniformity and also found that no batches found, drug content more than $30 \mathrm{mg}$, as shown in table 3.

In vitro drug release study showed that as the concentration of polymer increases the drug release from the unidirectional patch was decreased and also found, as the concentration of permeation enhancer dimethyl sulfoxide increases the drug release increased enormously and found to release the drug $96.89 \%$ in 24 hours for F5 batch F6 showed almost $80.61 \%$ of drug dissolved at 12 hours as shown in table 4 ; this is due to the high concentration of permeation enhancer used in F6 formulation. Patch prepared with hydroxypropyl methylcellulose E15 $200 \mathrm{mg}$ and $4 \% \mathrm{v}$ / v dimethyl sulfoxide (F5) showed better drug release is prolonged compared to F6 formulation. FTIR studies were done for pure drug and final formulation. From the spectra it was observed that there is no significant change in the final formulation, and this indicates that there is no interaction between drug and polymer as shown in table 2.

The in vitro release profile was applied in various kinetic models to find out the mechanism of drug release. The best fit with the highest correlation coefficient was shown in the Peppa's equation with $\mathrm{R}^{2}$ value of 0.9840 as given in table 5 , the highest correlation was observed in the Peppa's plot rather than other models. The log cumulative percentage of drug release was proportional to log time indicates the drug release from the transdermal patch is explained by " $n$ " value greater than 1 , and its release occurs in only one dimensional way shows diffusion, and follows super case II transport mechanism. 


\section{CONCLUSIONS}

In the present study, an optimised patch was developed for the transdermal delivery of ketorolac tromethamine. On the basis of in vitro release characterization, it was concluded that the KTR patch could be administered transdermally once daily, to prolong the blockage of inflammatory mediators.

Data sharing statement provided by the authors is available with the full text of this article at jemds.com.

Financial or other competing interests: None.

Disclosure forms provided by the authors are available with the full text of this article at jemds.com.

\section{REFERENCES}

[1] Prakash G, Venkata RI, Doddayya H, et al. Comparative Evaluation of selected vegetable oils and terpenes on transdermal permeation of ketorolac tromethamine. International Journal of Drug Development Research 2011;3(4):178-88.

[2] Sarkar G, Saha NR, Roy I, et al. Taro corms mucilage/HPMC based transdermal patch: an efficient device for delivery of diltiazem hydrochloride. Int J Biol Macromol 2014;66:158-65.

[3] Choi SY, Seop SY, Hyun MY, et al. Safety evaluation of topical valproate application. Toxicol Res 2013;29(2): 8790.
[4] Ma J, Wang C, Luo H, et al. Design and evaluation of a monolithic drug-in-adhesive patch for testosterone based on styrene-isoprene-styrene block copolymer. J Pharm Sci 2013;102(7):2221-34.

[5] Rhee YS, Nguyen T, Park ES, et al. Formulation and biopharmaceutical evaluation of a transdermal patch containing aceclofenac. Arch Pharm Res 2013;36(5):6027.

[6] Yang Z, Teng Y, Wang H, et al. Enhancement of skin permeation of bufalin by limonene via reservoir type transdermal patch: formulation design and biopharmaceutical evaluation. International Journal of Pharmaceutics 2013;447(1-2):231-40.

[7] Zhu YL, Song GH, Liu DQ, et al. Multicenter clinical study for evaluation of efficacy and safety of transdermal fentanyl matrix patch in treatment of moderate to severe cancer pain in Chinese cancer patients. Chin J Cancer Res 2011;23(4):317-22.

[8] Kshirasagar N, Pavani S, Adukondalu D, et al. Formulation and evaluation of sublingual strips of naratriptan. Indo American Journal of Pharmaceutical Science 2016;3(7);759-66.

[9] Kshirasagar N, Puchchakayala G, Balamurgan K. Formulation and evaluation of diclofenac diethylamine loaded microsponges containing gel as novel drug delivery system. Int J Pharma Res 2020;12(2). 